\title{
Comparison of Glucose and Fat as Energy Sources in Peripheral Parenteral Nutrition in Rats
}

\author{
Yasuhiko Fukuta, Kanji ArII, Akihiko Matsuda \\ and Yukifumi KoKuBA \\ Infusion Research Department, Medical Information Development Division, \\ Hoechst Marion Roussel Ltd., Shiga 520-2313, Japan
}

(Received July 3, 1997)

\begin{abstract}
Summary Glucose is usually chosen as the energy source for total parenteral nutrition. However, the optimal glucose : fat ratio for peripheral parenteral nutrition has not been examined sufficiently. We compared glucose: fat ratios in hypocaloric nutrition. Male SD rats were given hypocaloric parenteral nutrition (approx. $190 \mathrm{kcal} / \mathrm{kg} / \mathrm{d}$ ) for $5 \mathrm{~d}$ after laparotomy. The hypocaloric solutions used contained $0,33,50,67$ or $100 \%$ of the non-protein energy in the form of fat. Body weight change, nitrogen balance, organ weights, and hepatic, splenic and plasma biochemistries were assessed. Body weight increase in the 67 and $100 \%$ fat groups was significantly greater than that in the $0 \%$ fat group. Nitrogen balance was the same in all groups. Hepatic glycogen content was significantly lower in the $100 \%$ fat group than that in the $0 \%$ fat group. The weight of epididymal fat deposits was significantly lower in the $0 \%$ fat group than in the 50 and $67 \%$ fat groups. On the other hand, tissue triglyceride content and plasma lipid levels in the $100 \%$ fat group were significantly higher than in the $0 \%$ fat group, and were also higher than in the control group. It is suggested that combinations of glucose and fat have sparing effects on body fat and hepatic glycogen. Combinations of glucose and fat as non-protein energy sources were superior to glucose or fat alone for hypocaloric parenteral nutrition.

Key Words rat, peripheral parenteral nutrition, laparotomy, glucose, fat emulsion
\end{abstract}

Peripheral parenteral nutrition (PPN) has been developed for reasons of safety, simplicity and cost. The use of PPN avoids certain disadvantages seen in total parenteral nutrition, such as complexity of technique and catheter-related sepsis $(1,2)$. However, PPN also has disadvantages such as thrombophlebitis, which is a serious problem (3) and limits the amount of energy that can be supplied. The causes of thrombophlebitis are thought to be the $\mathrm{pH}(4)$, osmolarity (5) and titratable acidity (6) of the solution. To avoid increases in the osmotic pressure of the solution and provide energy sources effectively via the peripheral vein, fat emulsions are frequently 
chosen as principal energy sources because they exert no osmotic pressure and contain more energy per gram than glucose. Yamazaki et al (7) showed that PPN fat emulsion had a nitrogen-sparing effect and was therefore as effective as glucose in injured rats, and Skillman et al (8) and Dworkin et al (9) obtained similar results in clinical studies. Glucose-amino acid and fat-amino acid mixtures showed similar effects on nitrogen balance in these studies. Glucose: fat ratios in total parenteral nutrition have been studied extensively, and the optimal fat proportion is approximately $30 \%$ of the non-protein energy sources (10-12). However, the optimal glucose : fat ratio in PPN, and the relative values of glucose and fat as energy sources are unclear. Recently, Smith et al (13) and Kohlhardt et al (14) showed that 70-75\% of the non-protein energy sources could be provided in the form of fat via the peripheral vein. However, the optimal glucose : fat ratio for PPN is still uncertain.

This study using laparotomized rats was carried out in order to investigate the nutritional effects of hypocaloric solutions containing different glucose : fat ratios.

\section{MATERIALS AND METHODS}

Animals and PPN solutions. Male Sprague-Dawley rats weighing 160-180 g were purchased from Charles River Japan Inc. (Shiga, Japan). The rats were kept in a restricted access room with controlled temperature $\left(23 \pm 2^{\circ} \mathrm{C}\right)$, humidity $(55 \pm 15 \%)$ and lighting (from 07:00 to 19:00 h), and were given commercial feed (CRF-1; Oriental Yeast Co., Tokyo, Japan).

The test solutions were prepared using a commercial $50 \%$ glucose solution, $10 \%$ fat emulsion, a mixture of amino acid and electrolyte solution (without sodium dihydrogenphosphate), sodium dihydrogenphosphate solution, a commercial mixed-vitamin solution and injectable water. The $10 \%$ fat emulsion contained egg yolk lecithin and soybean oil, and was prepared specially using a Microfluidizer (M-110Y; Microfluidics Co., Newton, MA, USA) because commercial fat emulsions contain glycerol, which is an energy source. An amino acid-supplemented electrolyte solution was prepared in order to reduce the infusion volume. The amino acid composition was the same as that in a commercial amino acid solution (Aminic; Roussel Morishita Co., Osaka, Japan). The sodium dihydrogenphosphate solution was kept separate in order to avoid reaction with the calcium ions during autoclaving. Each solution was mixed aseptically prior to use. Non-protein energy of $0,33,50$, 67 or $100 \%$ was supplied as fat. The osmolarity of each solution was measured using an osmometer (OM 801; Vogel, Germany). The compositions of the test solutions are shown in Table 1.

Experimental design. Rats were divided into 6 groups: 0, 33, 50, 67 and 100\% fat infusion groups $(n=8)$, and a control group $(n=5)$. After overnight fasting, rats in the infusion groups underwent laparotomy ( $3 \mathrm{~cm}$ abdominal incision and suture) and jugular vein cannulation under pentobarbital anesthesia. After this operation, the rats were kept in metabolic cages and infused with the solutions for $5 \mathrm{~d}$. The dose was $189.4 \mathrm{kcal} / \mathrm{kg} / \mathrm{d}$ and nitrogen supply $1.23 \mathrm{~g} / \mathrm{kg} / \mathrm{d}$. Control rats were supplied 
Table 1. The compositions of the test solutions.

\begin{tabular}{lccccc}
\hline Composition & $0 \%$ fat & $33 \%$ fat & $50 \%$ fat & $67 \%$ fat & $100 \%$ fat \\
\hline Amino acids $(\mathrm{g} / \mathrm{L})$ & 30.0 & 30.0 & 30.0 & 30.0 & 30.0 \\
Glucose $(\mathrm{g} / \mathrm{L})$ & 145.0 & 96.7 & 72.5 & 48.3 & 0 \\
Fat $(\mathrm{g} / \mathrm{L})$ & 0 & 21.5 & 32.2 & 43.0 & 64.5 \\
Electrolytes & & & & & \\
$\quad$ Sodium $(\mathrm{mEq} / \mathrm{L})$ & 40 & 40 & 40 & 40 & 40 \\
Potassium $(\mathrm{mEq} / \mathrm{L})$ & 20 & 20 & 20 & 20 & 20 \\
Chlorine $(\mathrm{mEq} / \mathrm{L})$ & 40 & 40 & 40 & 40 & 40 \\
Calcium $(\mathrm{mEq} / \mathrm{L})$ & 5 & 5 & 5 & 5 & 5 \\
Phosphate $(\mathrm{mm})$ & 5 & 5 & 5 & 5 & 5 \\
Magnesium $(\mathrm{mEq} / \mathrm{L})$ & 5 & 5 & 5 & 5 & 5 \\
Zinc $(\mu \mathrm{M})$ & 5 & 5 & 5 & 5 & 5 \\
\hline Total energy $(\mathrm{kcal} / \mathrm{L})$ & 700 & 700 & 700 & 700 & 700 \\
\hline Osmolarity $(\mathrm{mOsm} / \mathrm{kg})$ & 1,344 & 1,009 & 855 & 695 & 398 \\
\hline
\end{tabular}

with CRF-1 and tap water ad libitum throughout the experimental period. Urine was collected from the infusion groups every day.

After infusion, all rats were anesthetized using pentobarbital, exsanguinated, and the liver, spleen and epididymal fat deposits removed. Urinary nitrogen was measured using an automatic analyzer (Yanako CN Corder; Yanagimoto Seisakusho Co., Kyoto, Japan). This animal experiment was approved by the Committee for the Care and Use of Laboratory Animals in our laboratory.

Biochemistry tests. Glucose and total protein were analyzed using an automatic analyzer (7150 type; Hitachi Co., Tokyo, Japan). Triglyceride in the plasma was measured using an assay kit (Determiner-TG-S555; Kyowa Medex Co., Tokyo, Japan), and non-esterified fatty acid (NEFA) was also measured using an assay kit (NEFA C-test Wako; Wako Pure Chemical Industries Co., Osaka, Japan).

The hepatic protein content was measured according to the method of Lowry et al (15), and the glycogen content was measured according to the method of Hossid and Abraham (16). Hepatic and splenic lipids were extracted according to the method of Folch et al (17), and the triglyceride content was measured using an assay kit (Triglyceride-test Wako; Wako Pure Chemical Industries Co., Osaka, Japan).

Statistical analysis. All data are presented as means \pm SE. Statistical significance was determined by analysis of variance and Dunnett's multiple comparison test using a statistical program system (Toukei Library ver. 4; Yukumus, Tokyo, Japan). Probability values $<0.05$ were considered statistically significant. 


\section{RESULTS}

Two rats in the $67 \%$ fat group were eliminated because the catheter was cut during infusion.

\section{Body weight change, nitrogen balance and organ weights}

Body weight change and cumulative nitrogen balance are shown in Fig. 1. Body weight change in the $0 \%$ fat group was slightly negative and significantly lower than that in the 67 and $100 \%$ fat groups. All infusion groups showed positive nitrogen balances, and there were no significant differences between groups. Relative weights of organs are shown in Table 2. Liver weight in the infusion groups was
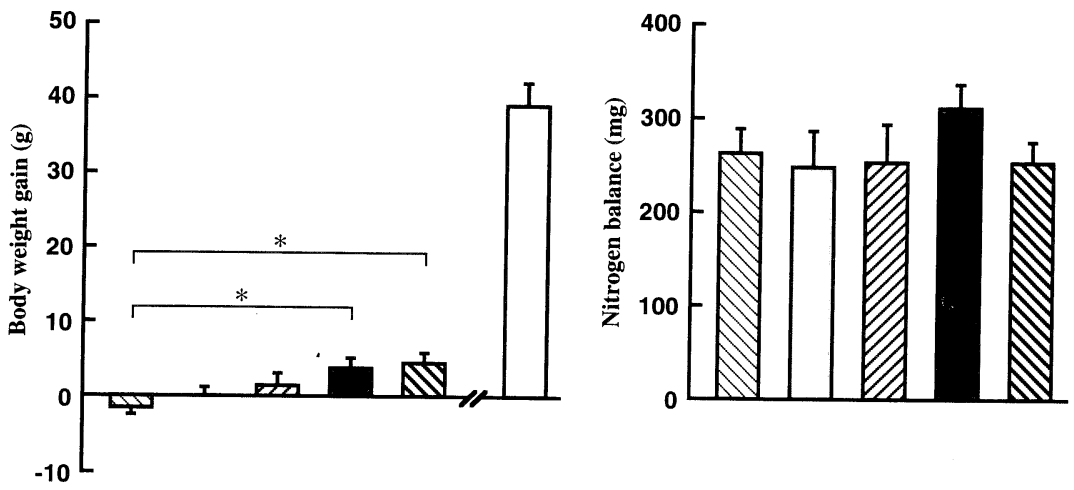

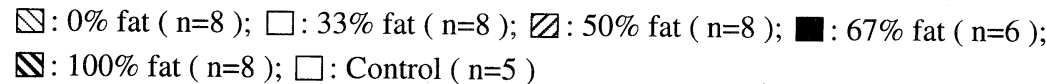

Fig. 1. Body weight gain and cumulative nitrogen balance during infusion of test solutions to laparotomized rats. Each column represents means \pm SE. * Significant differences at $p<0.05$.

Table 2. Relative weights of organs after infusion of test solutions in laparotomized rats.

\begin{tabular}{lcccc}
\hline Group & $n$ & Liver & Spleen & Epididymal fat deposits \\
\hline $0 \%$ fat & 8 & $3.29 \pm 0.07$ & $0.29 \pm 0.01$ & $0.57 \pm 0.03$ \\
$33 \%$ fat & 8 & $3.56 \pm 0.05^{*}$ & $0.27 \pm 0.01$ & $0.65 \pm 0.04$ \\
$50 \%$ fat & 8 & $3.63 \pm 0.08^{* *}$ & $0.31 \pm 0.02$ & $0.70 \pm 0.03^{*}$ \\
$67 \%$ fat & 6 & $3.78 \pm 0.06^{* *}$ & $0.31 \pm 0.02$ & $0.72 \pm 0.04^{*}$ \\
$100 \%$ fat & 8 & $3.39 \pm 0.05$ & $0.29 \pm 0.01$ & $0.66 \pm 0.04$ \\
\hline Control & 5 & $4.12 \pm 0.14$ & $0.25 \pm 0.02$ & $0.82 \pm 0.08$
\end{tabular}

Values are means $\pm \mathrm{SE}$, expressed as percentage of body weight. $p$ value compared with $0 \%$ fat group: $* p<0.05$ and $* * p<0.01$. 
lower than that in the control group, and that in the $0 \%$ fat group was significantly lower than in the 33, 50 and $67 \%$ fat groups. There were no significant differences in spleen weight. The weight of epididymal fat deposits in the infusion groups was lower than that in the control group, and in the $0 \%$ fat group, it was significantly lower than in the 50 and $67 \%$ fat groups.

\section{Plasma biochemistry}

The results are shown in Table 3. The concentrations of triglyceride and NEFA increased with the amount of fat infused. The triglyceride and NEFA concentrations in the 67 and $100 \%$ fat groups were higher than those in the control group. The concentration of glucose in the infusion groups was lower than that in the control group, and that in the $0 \%$ fat group was significantly lower than in the other

Table 3. Plasma biochemistry findings after infusion of test solutions in laparotomized rats.

\begin{tabular}{lcclll}
\hline Group & $n$ & $\begin{array}{c}\text { Triglyceride } \\
(\mathrm{mg} / 100 \mathrm{~mL})\end{array}$ & $\begin{array}{c}\text { NEFA } \\
(\mathrm{mEq} / \mathrm{L})\end{array}$ & $\begin{array}{c}\text { Glucose } \\
(\mathrm{mg} / 100 \mathrm{~mL})\end{array}$ & $\begin{array}{c}\text { Total protein } \\
(\mathrm{g} / 100 \mathrm{~mL})\end{array}$ \\
\hline $0 \%$ fat & 8 & $29.6 \pm 3.0$ & $0.02 \pm 0.00$ & $116.8 \pm 3.6$ & $4.57 \pm 0.05$ \\
$33 \%$ fat & 8 & $73.0 \pm 4.3$ & $0.12 \pm 0.01$ & $136.2 \pm 3.7^{* *}$ & $4.70 \pm 0.04$ \\
$50 \%$ fat & 8 & $76.7 \pm 3.2^{*}$ & $0.18 \pm 0.01^{*}$ & $141.5 \pm 3.2^{* *}$ & $4.70 \pm 0.05$ \\
$67 \%$ fat & 6 & $100.0 \pm 6.7^{* *}$ & $0.27 \pm 0.03^{* *}$ & $140.0 \pm 2.7^{* *}$ & $4.63 \pm 0.11$ \\
$100 \%$ fat & 8 & $431.0 \pm 67.5^{* *}$ & $0.30 \pm 0.04^{* *}$ & $135.0 \pm 3.4^{* *}$ & $4.46 \pm 0.05$ \\
\hline Control & 5 & $78.8 \pm 9.4$ & $0.19 \pm 0.03$ & $171.2 \pm 7.6$ & $5.11 \pm 0.06$ \\
\hline
\end{tabular}

Values are means \pm SE. $p$ value compared with $0 \%$ fat group: ${ }^{*} p<0.05$ and $* * p<0.01$.
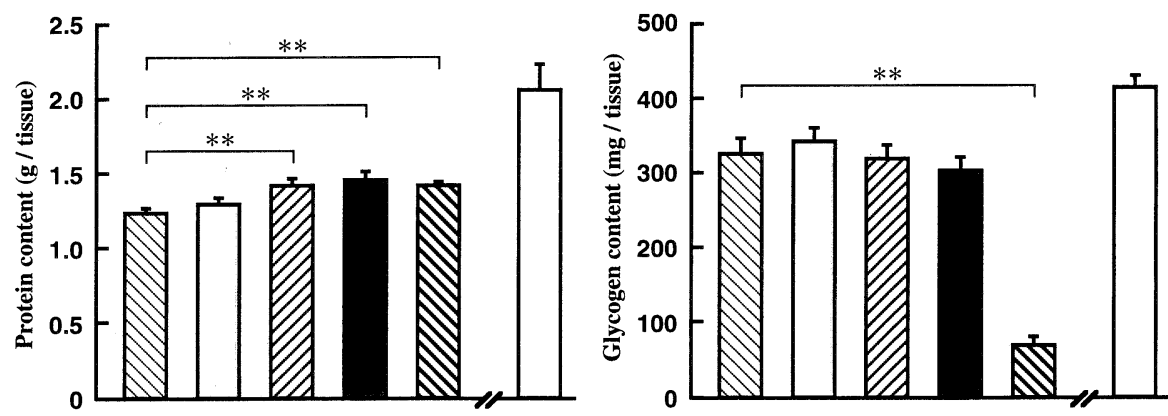
$\triangle: 0 \%$ fat $(\mathrm{n}=8)$;
$33 \%$ fat $(n=8) ; \square: 50 \%$ fat $(n=8)$
: $67 \%$ fat $(n=6)$

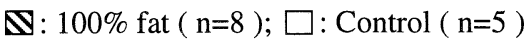

Fig. 2. Protein and glycogen contents in the liver after infusion of test solutions to laparotomized rats. Each column represents means \pm SE. ${ }^{* *}$ Significant differences at $p<0.01$. 

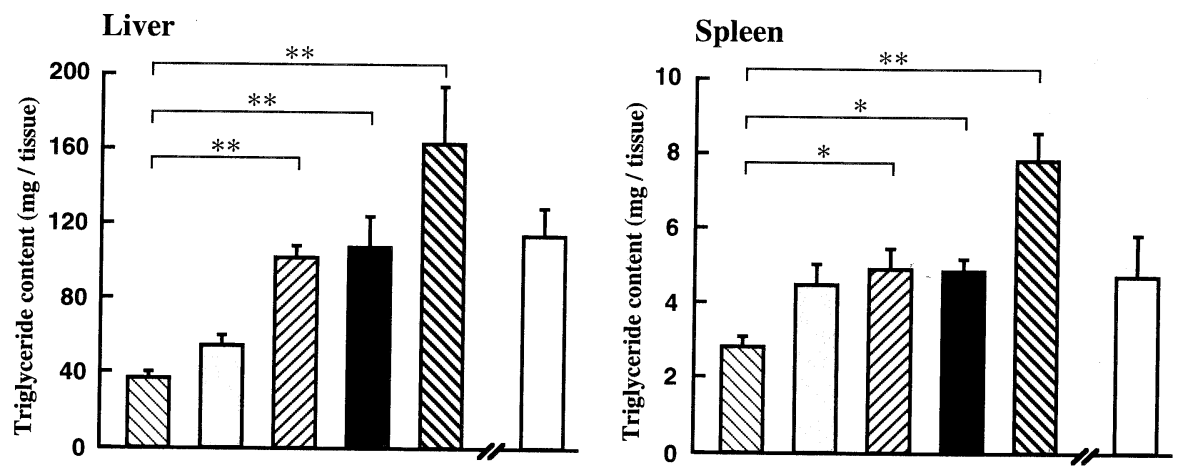

$\triangle: 0 \%$ fat $(\mathrm{n}=8) ; \square: 33 \%$ fat $(\mathrm{n}=8) ; \square: 50 \%$ fat $(\mathrm{n}=8) ; \square: 67 \%$ fat $(\mathrm{n}=6)$; $\mathbf{N}: 100 \%$ fat $(\mathrm{n}=8) ; \square:$ Control $(\mathrm{n}=5)$

Fig. 3. Triglyceride contents in the liver and spleen after infusion of test solutions to laparotomized rats. Each column represents means \pm SE. * and ** Significant differences at $p<0.05$ and $p<0.01$, respectively.

infusion groups. The concentration of total protein in the infusion groups was also lower than that in the control group, and there were no differences between the infusion groups.

\section{Organ biochemistry}

The protein and glycogen contents of the liver are shown in Fig. 2. Both protein and glycogen contents in the infusion groups were lower than those in the control group. Among the infusion groups, protein content in the $0 \%$ fat group was significantly lower than that in the 50,67 and $100 \%$ fat groups. Conversely, glycogen content in the $100 \%$ fat group was significantly lower than that in the $0 \%$ fat group. The triglyceride contents of the liver and spleen are shown in Fig. 3. Both of these values increased with the increased infusion of fat, and significant differences were observed between the $0 \%$ fat group and the 50,67 and 100\% fat groups. Moreover, the levels in the $100 \%$ fat group exceeded those in the control group.

\section{DISCUSSION}

In this study, rats were given approximately $190 \mathrm{kcal} / \mathrm{kg} / \mathrm{d}$, which is considered to be lower than their energy requirement, as Martins et al (10) showed that $270 \mathrm{kcal} / \mathrm{kg} / \mathrm{d}$ was suboptimal for normal rats, and that $350 \mathrm{kcal} / \mathrm{kg} / \mathrm{d}$ permitted more rapid weight gain than $270 \mathrm{kcal} / \mathrm{kg} / \mathrm{d}$. On the other hand, Chang and Silvis (18) showed that glucose infusions containing over $300 \mathrm{kcal} / \mathrm{kg} / \mathrm{d}$ invariably resulted in grossly fatty liver. On the basis of these reports, the energy level in this experiment was therefore estimated to be approximately two-thirds of the rats' requirements.

We prepared glycerol-free fat emulsions instead of using commercial fat 
emulsions because Brennan and Moore (19) showed that glycerol in fat emulsions has a protein-sparing effect. From the results of body weight gain and weight of epididymal fat deposits, it was suggested that solutions containing fat were superior to fat-free solution. On the other hand, in the $100 \%$ fat group, the hepatic and splenic triglyceride contents and the plasma lipid levels were higher than those in the control group. Although the effects of fat emulsions on the reticuloendothelial system are still controversial (20), the accumulation of lipids in the liver and spleen in the $100 \%$ fat group was not a favorable finding. In addition, this group showed a significant decrease in hepatic glycogen content. Gluconeogenesis from fat cannot occur, and this might be the cause of glycogen depletion in the $100 \%$ fat group. From these results, $100 \%$ fat is considered to be a non-optimal composition. With respect to protein metabolism, the protein content of the liver was lower in the $0 \%$ fat group than in the other infusion groups. In the $67 \%$ fat group, the plasma lipid levels were also higher than those in the control group. Moreover, it is generally thought that the amount of fat infusion from the vein for Japanese should not exceed $1-1.5 \mathrm{~g} / \mathrm{kg} / \mathrm{d}$. From this viewpoint, it is surmised that $67 \%$ fat as a non-protein energy source is somewhat high.

The amino acid and total energy contents of the solutions were $3 \%$ and $700 \mathrm{kcal} / \mathrm{L}$, respectively. The amino acid level was chosen on the basis of the findings of Hwang et al (21); even if energy intake is suboptimal, at least $1 \mathrm{~g} / \mathrm{kg} / \mathrm{d}$ of amino acids should be infused in surgical patients. If $2,000 \mathrm{~mL} / \mathrm{d}$ of the solutions used in this study were infused into humans, amino acid intake would be $60 \mathrm{~g} / \mathrm{d}$. With amino acid concentration at $1 \mathrm{~g} / \mathrm{kg} / \mathrm{d}$ in a $700 \mathrm{kcal} / \mathrm{L}$ solution, the osmolarity of the $33 \%$ fat solution was over $1,000 \mathrm{mOsm} / \mathrm{kg}$. The osmotic pressure of solutions for peripheral infusion should not exceed 800 to $1,000 \mathrm{mOsm} / \mathrm{L}(3,22,23)$, and the $33 \%$ fat solution used in this study would therefore not be available for PPN without using especially long catheters $(24,25)$. PPN is a useful technique, and our results suggest that $1,400 \mathrm{kcal} / 2,000 \mathrm{~mL}$ can be provided by using fat emulsion. However, the energy level is restricted when compared with TPN. If parenteral nutritional management lasts more than $7-10 \mathrm{~d}$, TPN will be better than PPN.

In conclusion, a combination of glucose and fat as the non-protein energy sources in PPN was superior to either glucose or fat as the sole non-protein energy source. From the results of the osmotic pressure of the solution and lipid metabolism, $50 \%$ fat as a non-protein energy source was optimal in our PPN regimen.

\section{REFERENCES}

1) Hansell DT. 1989. Intravenous nutrition: The central or peripheral route? Intensive Ther Clin Monitor 10: 184-190.

2) Stokes MA, Hill GL. 1993. Peripheral parenteral nutrition: A preliminary report on its efficacy and safety. JPEN 17: 145-147.

3) Payne-James JJ, Khawaja HT. 1993. First choice for total parenteral nutrition: The

Vol 44, No 1, 1998 
peripheral route. JPEN 17: 468-478.

4) Fonkalsrud EW, Murphy J, Smith FG. 1968. Effect of pH in glucose infusions on development of thrombophlebitis. J Surg Res 8: 539-543.

5) Timmer JG, Schipper HG. 1991. Peripheral venous nutrition: the equal relevance of volume load and osmolarity in relation to phlebitis. Clin Nutr 10: 71-75.

6) Kuwahara T, Asanami S, Tamura T, Kubo S. 1996. Experimental infusion phlebitis: importance of titratable acidity on phlebitic potential of infusion solution. Clin Nutr 15: $129-132$.

7) Yamazaki K, Maiz A, Sobrado J, Babayan V, Moldawer LL, Bistrian BR, Blackburn GL. 1984. Hypocaloric lipid emulsion and amino acid metabolism in injured rats. JPEN 8: $361-366$.

8) Skillman JJ, Rosenoer VM, Pallotta JA, Young JB, Young VR, Long PC, Wilentz K, Munro HN. 1981. Effect of isocaloric fat or glucose on albumin synthesis and nitrogen balance in patients receiving amino acid infusion. Surgery 89: 168-174.

9) Dworkin B, Daly J, Massar E, Alcock N, Dudrick SJ, Copeland EM III. 1983. Intravenous administered amino acids with either dextrose or lipid as nutritional support in surgical patients. Surg Gynecol Obstet 156: 577-581.

10) Martins FM, Wennberg A, Kihlberg R, Meurling S, Lindmark L. 1985. Total parenteral nutrition with different ratios of fat/carbohydrate at two energy levels: An animal study. JPEN 9: 47-52.

11) Linza-Jacoby S, Tabares A, Sitren HS, Kosar E. 1987. Comparison of glucose and glucose plus lipid as caloric sources in parenterally fed rats. Am $J$ Physiol 253: E158-E164.

12) Ash SA, Griffin GE, Stock MJ. 1989. Non-protein energy source in parenterally fed weanling rats influences growth, body composition, and skeletal muscle protein turnover. Clin Nutr 8: 49-55.

13) Smith RC, Mackie W, Kohlhardt SR, Kee AJ. 1992. The effect on protein and amino acid metabolism of an intravenous nutrition regimen providing seventy percent of nonprotein calories as lipid. Surgery 111: 12-20.

14) Kohlhardt SR, Smith RC, Kee AJ. 1994. Metabolic response to a high-lipid, high nitrogen peripheral intravenous nutrition solution after major upper-gastrointestinal surgery. Nutrition 10: 317-326.

15) Lowry OH, Rosebrough NJ, Lewis FA, Randall RJ. 1951. Protein measurement with the folin phenol reagent. $J$ Biol Chem 193: 265-275.

16) Hossid WZ, Abraham S. 1957. Chemical procedures for analysis of polysaccharides. Determination of glycogen with anthrone reagent. In: Methods in Enzymology (Colowick SP, Kaplan NO, eds), Vol III, p 34. Academic Press, New York.

17) Folch J, Lees M, Stanley GHS. 1957. A simple method for the isolation and purification of total lipids from animal tissue. J Biol Chem 226: 497-509.

18) Chang S, Silvis SE. 1974. Fatty liver produced by hyperalimentation of rats. Am J Gastroenterol 62: 410-418.

19) Brennan MF, Moore FD. 1973. An intravenous fat emulsion as a nitrogen sparer: Comparison with glucose. J Surg Res 14: 501-504.

20) Palmblad J. 1991. Intravenous lipid emulsions and host defense-a critical review. Clin Nutr 10: 303-308.

21) Hwang TL, Mou SC, Chen MF. 1993. The importance of a source of sufficient protein in postoperative hypocaloric partial parenteral nutrition support. JPEN 17: 254-256.

22) Setnikar I, Paterlini MR. 1960. Osmotic pressure and tolerance of injectable solutions. 
J Am Pharm Assoc 49: 5-7.

23) Messing B, Leverve X, Rigaud D, Krummel Y, Botta D, Latarget J, Mudry P, Guignier M. 1986. Peripheral venous complications of a hyperosmolar (960 mOsm) nutritive mixture: The effect of heparin and hydrocortisone. A multicenter double-blinded random study in 98 patients. Clin Nutr 5: 57-61.

24) Madan M, Alexander DJ, McMahon MJ. 1992. Influence of catheter type on occurrence of thrombophlebitis during peripheral intravenous nutrition. Lancet 339: 101-103.

25) Kane KF, Cologiovanni L, McKiernan J, Panos MZ, Ayres RCS, Langman MJS, Lowes JR. 1996. High osmolality feedings do not increase the incidence of thrombophlebitis during peripheral iv nutrition. JPEN 20: 194-197. 